\title{
Sodium chloride pica causing recurrent nephrolithiasis in a patient with iron deficiency anemia: a case report
}

\author{
Brittany Rogers ${ }^{1}$, Joshua Kramer ${ }^{1}$, Stephanie Smith ${ }^{2}$, Vincent Bird ${ }^{3}$ and Eric I. Rosenberg ${ }^{1 *}$
}

\begin{abstract}
Background: Iron deficiency anemia is a common finding in women of child-bearing age. Pica, or the ingestion of non-food or non-nutritive items, is a well-known manifestation of iron deficiency. A high sodium diet increases risk for nephrolithiasis. We describe the case of a 31-year-old woman with recurrent calcium nephrolithiasis and anemia who ate ice chips as well as spoons of salt daily. Treatment of pica may prove effective in preventing recurrent nephrolithiasis.

Case presentation: A 31-year-old white woman with a past medical history of menorrhagia, anemia, and recurrent calcium nephrolithiasis presented for preoperative evaluation prior to ureterolithotomy. She described a daily pattern of eating continually from a cup of ice chips accompanied by multiple spoons of salt directly out of a salt shaker. These cravings had been present for many years, were bothersome to her, and interfered with her daily life. Laboratory findings revealed hemoglobin of $10.9 \mathrm{~g} / \mathrm{dL}$ with ferritin of $3 \mathrm{ng} / \mathrm{mL}$. History, physical, and laboratory data were consistent with pica secondary to iron deficiency anemia. She was prescribed orally administered ferrous sulfate $325 \mathrm{mg}$ three times a day with meals. She continues to struggle with the symptoms of pica and orally administered supplementation.

Conclusions: It is important that clinicians consider the possible diagnosis of sodium chloride pica in patients with iron deficiency anemia and recurrent nephrolithiasis. Treatment of anemia and resolution of pica may prove effective in preventing future nephrolithiasis. Specific questioning about pica symptoms in patients with iron deficiency anemia and recurrent nephrolithiasis may be helpful diagnostically and therapeutically.
\end{abstract}

Keywords: Pica, Anemia, Iron deficiency, Nephrolithiasis, Case report

\section{Background}

Pica is a well-known physical manifestation of nutrient deficiency, most commonly iron. Cravings for nonnutritive food items including sand or clay (geophagia), gravel or stone (lithophagia), ice (pagophagia), and starch (amylophagia) become compulsions that interfere with the patient's day-to-day life. It has been estimated that pica occurs in as many as $50 \%$ of patients with iron deficiency anemia [1]. Pica is most frequently seen in pregnant women, children, and people of low socioeconomic class. Pica has been documented in written

\footnotetext{
* Correspondence: eir@ufl.edu

'Department of Medicine, Division of General Internal Medicine, College of Medicine, University of Florida, 1329 SW 16th Street, Suite 5140, Gainesville, FL 32610, USA

Full list of author information is available at the end of the article
}

history since the time of Hippocrates [2]. The long-term consequences of pica are not well understood; toxicity from metabolic abnormalities arising from elemental and vitamin deficiencies, as well as bowel obstruction, excessive calorie intake, and dental damage have all been observed in the short term [3]. In some patients, pica symptoms may be short lived, but in other patients the symptoms may persist for longer periods undiagnosed and have more adverse health effects.

Sodium chloride pica is a very rare form of pica [4]. In 1985, Shapiro and Linus described a 33-year-old woman with hypertension and history of dysfunctional uterine bleeding who experienced very similar salt cravings and was diagnosed with salt pica secondary to iron deficiency anemia [4]. Her pica symptoms and anemia resolved following treatment with a 4-week course of parenteral 
iron following failure of 1 month of orally administered iron therapy. A high sodium diet increases risk for nephrolithiasis. In a patient with normal renal function, increased sodium intake is excreted by the kidneys to maintain homeostasis. Increased sodium excretion promotes calcium excretion which facilitates the formation of calcium stones [5].

\section{Case presentation}

A 31-year-old white woman with a past medical history of menorrhagia, anemia, and recurrent calcium nephrolithiasis presented for preoperative evaluation prior to ureterolithotomy. She described a daily pattern of eating continually from a cup of ice chips accompanied by multiple spoons of salt directly out of a salt shaker. These cravings had been present for many years, were bothersome to her, and interfered with her daily life. She noticed an acute worsening of these symptoms following delivery of her last child. She described 5 days of heavy bleeding during her menstrual cycle. She denied chalk, clay, or dirt cravings. She denied lightheadedness, syncope or near syncope, or melena.

On physical examination, her temperature was $36.7^{\circ}$ C, blood pressure was $119 / 70 \mathrm{mmHg}$, heart rate was 88 beats per minute, respirations were 20 per minute, and oxygen saturation was $100 \%$ on room air. Her body mass index (BMI) was $26.3 \mathrm{~kg} / \mathrm{m}^{2}$. She was a well-nourished, well-developed woman. A physical examination was negative for stomatitis, glossitis, or pallor. An abdominal examination was negative for splenomegaly. Mentation was appropriate. Mood and affect were normal. Initial laboratory findings including hematology and iron studies are shown in Table 1. Previous stone analysis is shown in Table 2.

History, physical, and laboratory data were consistent with pica secondary to iron deficiency anemia. The differential diagnosis for her iron deficiency anemia included principally menorrhagia but consideration was also paid to possible occult gastrointestinal blood loss due to occult peptic ulcer disease, inflammatory bowel disease, parasitosis, malabsorption, or celiac disease. She had no history of diarrhea or abnormal constipation patterns. She had no history of weight loss, abdominal cramping, or pain. She described no international travel and had no history of exposure to untreated well-water. She had no history of nonsteroidal anti-inflammatory drug (NSAID) use.

She was prescribed ferrous sulfate $325 \mathrm{mg}$ administered orally three times a day with meals. She was hospitalized 3 months later for pain related to recurrent kidney stones. At that time, she reported that she had not been the taking the orally administered iron supplementation which had been prescribed. Her anemia worsened, as seen in Table 1.
Table 1 Hematology and iron profile

\begin{tabular}{llll}
\hline & Initial consult & 3 Months later & Normal range \\
\hline WBC & 7.6 & 4.8 & $\begin{array}{l}4.0-10.0 \\
\text { thousand } / \mathrm{mm}^{3}\end{array}$ \\
RBC & 4.57 & 4.26 & $4.0-5.2 \mathrm{million} / \mathrm{mm}^{3}$ \\
Hemoglobin & 10.9 & 9.1 & $12.0-16.0 \mathrm{~g} / \mathrm{dL}$ \\
Hematocrit & 33.9 & 28.0 & $35.0-45.0 \%$ \\
MCV & 74.2 & 67.4 & $78.0-100.0 \mathrm{\mu m}^{3}$ \\
MCH & 24.0 & 21.9 & $26-34 \mathrm{pg}$ \\
RDW & $14.1 \%$ & $15.6 \%$ & $11.0-14.0 \%$ \\
Reticulocyte & $1.2 \%$ & - & - \\
count & & & $150-450$ \\
Platelets & 286 & 194 & thousand $/ \mathrm{mm}{ }^{3}$ \\
& & & $40-190 \mathrm{mcg} / \mathrm{dL}$ \\
Total iron & $22 \mathrm{mcg} / \mathrm{dL}$ & - & $250-450 \mathrm{mcg} / \mathrm{dL}$ \\
TIBC & $431 \mathrm{mcg} / \mathrm{dL}$ & - & $11-50 \%$ \\
Iron saturation & $5 \%$ & - & $10-154 \mathrm{ng} / \mathrm{mL}$ \\
Ferritin & $3 \mathrm{ng} / \mathrm{mL}$ & - & $188-341 \mathrm{mg} / \mathrm{dL}$ \\
\hline Transferrin & $323 \mathrm{mg} / \mathrm{dL}$ & - &
\end{tabular}

$M C H$ mean corpuscular hemoglobin, $M C V$ mean corpuscular volume $R B C$ red blood cells, $R D W$ random distribution of red cell width, $T I B C$ total iron-binding capacity, WBC white blood cells

She was telephoned to follow-up on her current symptoms. She was unable to tolerate the orally administered iron due to symptoms of nausea and dyspepsia. She stated that her pica symptoms continued to be constant throughout the day. She was advised to return to our clinic for further evaluation and to discuss alternative iron supplementation. She has continued to have intermittent adherence to follow-up for her anemia with her primary care physician, limiting further workup and treatment.

\section{Discussion}

It is important that clinicians consider sodium chloride pica in patients with iron deficiency anemia and recurrent nephrolithiasis, because treatment of anemia and resolution of pica may prove effective in preventing future nephrolithiasis. In patients with normal renal function, urine calcium excretion increases $0.6 \mathrm{mmol} /$ day per each $100 \mathrm{mmol} /$ day of excreted sodium [5]. A low sodium diet (less than $100 \mathrm{mEq} /$ day) facilitates proximal tubule sodium and calcium reabsorption and limits

Table 2 Stone analysis

\begin{tabular}{ll}
\hline Composition & Percentage \\
\hline Calcium oxalate monohydrate & $55 \%$ \\
Calcium phosphate hydroxyl form & $30 \%$ \\
Calcium oxalate dehydrate & $7 \%$ \\
Calcium phosphate carbonate & $5 \%$ \\
Protein & $3 \%$ \\
\hline
\end{tabular}


calcium excretion into the urine [6]. It has been shown that decreasing sodium intake from 200 to $80 \mathrm{mEq} /$ day can decrease calcium excretion by $100 \mathrm{mg} /$ day ( 2.5 $\mathrm{mmol} /$ day) [7].

Our patient was unable to complete a 24-hour urine collection to confirm our hypothesis and exclude other possibilities. We anticipate this study would have revealed elevated urinary sodium and calcium concentrations. Metabolic evaluation and potassium citrate therapy should be considered for young adult patients with a stone to prevent recurrence. Oxalate seems to be the most significant urinary stone risk factor in this population followed by calcium and uric acid [8]. In addition to each individual risk factor, it appears that supersaturation with the sum of risk factors probably has the highest predictive value. Hypocitraturia should always be considered, confirmed by 24-hour urine; it is present in 30\% of patients who are stone formers, more so in men [9]. Young age (18 to 29 years) at first stone presentation was a significant risk factor for stone recurrence, and urinary citrate excretion was an independent risk factor affecting recurrence in this group [10].

Pica is included in the "Feeding and Eating Disorders" section of the Diagnostic and Statistical Manual of Mental Disorders, Fifth Edition (DSM-V) [11]. It has been linked with obsessive compulsive disorder (OCD), addictive behaviors, and family stress. These patients often exhibit awareness of obsessive cravings and acts of pica, but are unable to stop the compulsions. Pica occurs in patients of all educational backgrounds, but there is a high prevalence rate in individuals with intellectual disability. As with our patient, symptoms of pica may go undiagnosed for years. A patient may go to extreme measures to hide symptoms from friends and family members and be hesitant to discuss these behaviors with physicians.

In a patient with iron deficiency anemia and recurrent nephrolithiasis, using open-ended, non-judgmental questions such as "Do you have any cravings?" and explaining that "It is common for patients with anemia to experience certain cravings" will increase the likelihood of unmasking previously missed pica [12]. Giving examples of different common pica cravings can be beneficial as a patient may view eating ice chips or salt as benign or normal. If a nutrient deficiency is determined to be the cause of pica, replacing the depleted nutrient tends to reduce the behavior. However, cognitive behavioral therapy and family support may also be needed to completely resolve symptoms [12].

\section{Conclusions}

We described a rare case of sodium chloride pica associated with recurrent nephrolithiasis. It is important that clinicians consider the possible diagnosis of sodium chloride pica in patients with iron deficiency anemia and recurrent nephrolithiasis. Treatment of anemia and resolution of pica may prove effective in preventing future nephrolithiasis. Specific questioning about pica symptoms in patients with iron deficiency anemia and recurrent nephrolithiasis may be helpful diagnostically and therapeutically.

\section{Acknowledgements}

There were no additional contributors to this clinical vignette.

\section{Funding}

Not applicable.

Availability of data and materials

The data presented in this manuscript are fully anonymous.

\section{Authors' contributions}

$\mathrm{BR}, \mathrm{JK}, \mathrm{SS}, \mathrm{VB}$, and ER provided major contributions to the writing and preparation of the manuscript. Patient care was provided by VB and ER. All authors read and approved the manuscript.

Ethics approval and consent to participate

Not applicable.

\section{Consent for publication}

Written informed consent was obtained from the patient for publication of this case report and any accompanying images. A copy of the written consent is available for review by the Editor-in-Chief of this journal.

\section{Competing interests}

The authors declare that they have no competing interests.

\section{Publisher's Note}

Springer Nature remains neutral with regard to jurisdictional claims in published maps and institutional affiliations.

\section{Author details}

${ }^{1}$ Department of Medicine, Division of General Internal Medicine, College of Medicine, University of Florida, 1329 SW 16th Street, Suite 5140, Gainesville, FL 32610, USA. ${ }^{2}$ Department of Clinical and Health Psychology, College of Public Health and Health Professions, University of Florida, Florida, USA.

${ }^{3}$ Division of Minimally Invasive Surgery, Department of Urology, College of Medicine, University of Florida, Florida, USA.

Received: 20 July 2017 Accepted: 25 October 2017

Published online: 18 November 2017

\section{References}

1. Crosby WH. Pica. JAMA. 1976;235(25):2765

2. Woywodt A, Kiss A. Geophagia: the history of earth-eating. J R Soc Med. 2002:95(3):143-6.

3. Rose EA, Porcerelli JH, Neale AV. Pica: common but commonly missed. JABFP. 2000;13(5):353-8.

4. Shapiro MD, Linus SL. Sodium chloride pica secondary to iron-deficiency anemia. Am J Kidney Dis. 1985:5(1):67-8.

5. Lemann J. Pathogenesis of idiopathic hypercalciuria and nephrolithiasis. In: Coe FL, Favus MJ, editors. Disorders of Bone and Mineral Metabolism. New York: Ravens Press; 1992. p. 685-706.

6. Borghi L, Schianchi T, Meschi T, et al. Comparison of two diets for the prevention of recurrent stones in idiopathic hypercalciuria. N Engl J Med. 2002;346(22):77-83.

7. Muldowney FP, Freaney R, Moloney MF. Importance of dietary sodium in the hypercalciuria syndrome. Kidney Int. 1982;22(3):292

8. Parvin M, Shakhssalim N, Basiri A, et al. The most important metabolic risk factors in recurrent urinary stone formers. Urol J. 2011;8(2):99-106.

9. Ennis JL, Asplin JR. The role of the 24-h urine collection in the management of nephrolithiasis. Int J Surg. 2016;36(Pt D):633-7. 
10. Kang HW, Seo SP, Kim WT, et al. Metabolic characteristics and risks associated with stone recurrence in Korean young adult stone patients. J Endourol. 2017;31(8):806-11.

11. American Psychiatric Association. Diagnostic and statistical manual of mental disorders. 5th ed. Arlington: American Psychiatric Publishing; 2013.

12. Johnson BE. Pica. In: Walker HK, Hall WD, Hurst JW, editors. Clinical methods: the history, physical, and laboratory examinations. 3rd ed. Boston: Butterworths; 1990. p. 709

Submit your next manuscript to BioMed Central and we will help you at every step:

- We accept pre-submission inquiries

- Our selector tool helps you to find the most relevant journal

- We provide round the clock customer support

- Convenient online submission

- Thorough peer review

- Inclusion in PubMed and all major indexing services

- Maximum visibility for your research

Submit your manuscript at www.biomedcentral.com/submit 